\title{
Applicability of Saliva for Evaluation of Some Biochemical Parameters of Kidney and Liver Function in Healthy Individuals
}

Nasir M. Idkaidek iD

(PhD) Department of Pharmaceutical Technology, College of Pharmacy, University of Petra, Amman, Jordan.

Hiba A. Qawasmi (it)

(MSc) Department of Pharmaceutical Technology, College of Pharmacy, University of Petra, Amman, Jordan.

Alaa A. Hanahen

(MSc)Department of Pharmaceutical Technology, College of Pharmacy, University of Petra, Amman, Jordan.

Luay F. Abu-Qatouseh

$(\mathrm{PhD})$ Department of Pharmacology, College of Pharmacy, University of Petra, Amman, Jordan.

\section{Salim A. Hamadi (iD)}

(PhD)Department of Pharmacology, College of Pharmacy, University of Petra, Amman, Jordan.

Mona M. Bustami

(PhD)Department of Pharmacology,

College of Pharmacy, University of Petra, Amman, Jordan.

Corresponding author: Nasir M. Idkaidek

Email: nidkaidek@uop.edu.jo

Tel: +962(6)5799555

Address: University of Petra, Department of Pharmaceutical Technology, College of Pharmacy, Amman, Jordan

\section{Received: 2020/03/25}

Revised: 2020/05/3

Accepted: 2020/05/8

\section{cc) (7) (8)}

This work is licensed under a Creative Commons Attribution 4.0 License.

DOI : $\underline{10.29252 / \mathrm{mlj} .14 .4 .1}$

\begin{abstract}
Background and objectives: Proper diagnosis of clinical conditions is a major goal of clinical and biochemical analyses. Recently, increasing efforts have been put on the use of less invasive sampling techniques with optimal sensitivity and specificity. The aim of this study was to investigate the applicability of saliva instead of blood for measuring biochemical parameters of liver and kidney function in healthy individuals.

Methods: Plasma and saliva samples were collected from 100 healthy volunteers to measure level of alkaline phosphatase (ALP), alanine transaminase (ALT), aspartate aminotransferase (AST), total bilirubin, gamma-glutamyl transpeptidase (GGT), urea and creatinine using a fully automated chemistry analyzer (ACE Alera) with ready to use validated kits. Receiver operating characteristic (ROC) analysis was carried out using MediCal program to calculate sensitivity and specificity and area under ROC (AUC).
\end{abstract}

Results: The mean (standard deviation) salivary level of ALP, AST, ALT, GGT, total bilirubin, creatinine and urea was 20.9 (20.7) U/L, 25.8 (17.9) U/L, 10.6 (11.8) U/L, 9.6 (4.37) U/L, 0.16 $(0.13) \mathrm{mg} / \mathrm{dL}, \quad 0.09(0.05) \mathrm{mg} / \mathrm{dL}$ and $35.6 \quad(15.2) \mathrm{mg} / \mathrm{dL}$, respectively. Saliva to blood ratios of ALP, AST, ALT, GGT, total bilirubin, creatinine and urea was $14 \%, 113 \%, 65 \%, 45 \%$, $19 \%, 12 \%$ and $130 \%$, respectively. The suggested normal saliva ranges of ALP, AST, ALT, GGT, total bilirubin, creatinine and urea were 7-98 (U/L), 31-104 (U/L), 6-31 (U/L), 15-24 (U/L), 00.13 (mg/ dL), 0.14-0.31 (mg/ dL) and 45-74 (mg/ dL), respectively. The calculated sensitivity and specificity values were $38 \%$ and $85 \%$ for ALP), $80 \%$ and $76 \%$ for AST, $75 \%$ and $45 \%$ for ALT, $60 \%$ 91\% for GGT, $49 \%$ and $38 \%$ for total bilirubin, $20 \%$ and $91 \%$ for creatinine and $100 \%$ and $75 \%$ for urea. The AUC was higher than 0.7 for urea, GGT and AST, indicating good sensitivity and specificity of saliva testing for evaluation of these enzymes.

Conclusion: Based on the results, saliva could be as a noninvasive method of assessing kidney and liver function. Saliva may be a favorable alternative to plasma for measuring level of urea, GGT and AST in humans.

Keywords: Kidney function test, Liver function test, saliva. 


\section{INTRODUCTION}

Early diagnosis is crucial to decrease disease severity, avoid complications and enhance success rate of therapy. Saliva is an oral fluid that mirrors the body's health and wellbeing since it contains biomolecules that circulate in the bloodstream (1). Saliva has several functions including lubrication, assistance in speech and digestion as well as general maintenance of oral health. Mucus saliva also protects oral mucosa from irritants and infections. In addition, the buffering capacity of saliva protects teeth enamel from acidic damage and helps in re-mineralization (2-4). These functions of saliva are due to its various chemical components that constitute approximately $99 \%$ water, a variety of electrolytes(sodium, potassium, calcium, magnesium and phosphate) and proteins such as enzymes, immunoglobulins, antimicrobial factors, albumin, polypeptides and oligopeptides, traces of albumin and mucosal glycoproteins of great importance for maintaining oral health. It also contains glucose, urea and ammonia in various quantities that can interact and be responsible for several diseases (5-7). The components of saliva are either inherent components of saliva itself or are derived from blood. Plasma components could also enter saliva through various processes such as ultrafiltration through gap junctions, intercellular, transudation of plasma compounds into oral cavity through crevicular fluid and by passive diffusion of lipophilic molecules (8).

Saliva has several advantages over serum or other body fluids that makes it a valuable diagnostic tool including the non-invasive sampling, cost-effectiveness, minimal risk of cross-contamination, commercial availability and applicability to all patients, especially to those for whom blood sampling could be a challenge such as children and anxious or uncooperative patients $(1,9)$. Furthermore, a good correlation between concentration of serum and saliva has been reported for some but not all analytes (10).

Diagnostic disadvantages of saliva include variations in sample collection and diurnal/circadian rhythm as well as the necessity of sensitive detection systems $(11,12)$. Nevertheless, development of newer and sensitive technologies has enabled identification of biomolecules even in small quantities, which enhances the usability of saliva as a diagnostic tool (13-15).

Over the past few decades, saliva testing has been used for diagnosis of various oral and systemic diseases, some malignancies and infections $(1,16,17)$. A study on patients with late stage chronic kidney disease showed an elevated level of salivary urea with a positive correlation to blood urea levels (18). Saliva can be also used for therapeutic drug monitoring (19). Furthermore, the successful application of salivary diagnostics has been made possible by utilizing novel molecular approaches including transcriptomics, proteomics and genomics (20).

The aim of this study is to investigate the possibility of using saliva matrix instead of blood to detect level of alkaline phosphatase (ALP), alanine transaminase (ALT), aspartate aminotransferase (AST), total bilirubin, gamma-glutamyl transpeptidase (GGT), urea and creatinine and to characterize their normal range in healthy subjects.

\section{MATERIALS AND METHODS}

This randomly controlled cross sectional study was conducted from February 2019 to August 2019 after obtaining ethical approval from institutional review board of the University of Petra (IRB\#2H-7-2018). Written consent form was obtained from all participants. A total of 100 healthy normal individuals (43 males and 47 females) with no apparent underlying clinical condition were included in the study. The sample size was calculated after assuming $80 \%$ power and $5 \%$ significant level, while the relative risk of failure of the experimental subjects was 0.15. Individuals who were under medication for any reason were excluded from the study.

Demographic characteristics including age, sex, smoking habits and weight were collected using a questionnaire. Before collecting saliva samples, the participants were asked to gently rinse their mouth with water twice, to avoid any food residues contamination. The subjects sat with their heads in bent position. At least 1 $\mathrm{ml}$ of saliva was collected in a sterile container by simple spitting without stimulation. Subsequently, saliva samples were centrifuged at 1,500 rpm for 10 minutes, and the supernatant was used for biochemical analysis. In addition, $3 \mathrm{ml}$ of venous blood were collected in plain tubes and set to clot for 20 
Biosystems Co.) under the following conditions: initial denaturation at $95{ }^{\circ} \mathrm{C}$ for 10 minutes, and 40 cycles of denaturation at 95 ${ }^{\circ} \mathrm{C}$ for 15 seconds, annealing at $60{ }^{\circ} \mathrm{C}$ for 40 minutes. Then, the blood samples were centrifuged at 10,000 RPM for 15 minutes to collect serum. Both salivary and serum samples were analyzed within one hour of collection and the remaining content was stored at -20 OC.

Level of AST, ALT, ALP, GGT, total bilirubin, creatinine and urea were evaluated to assess liver and kidney function. All experiments were performed in the clinical biochemistry laboratory of the university of Petra pharmaceutical center (UPPC) using calibrated fully automated chemistry analyzer ACE ALERA II (Alfa Wassermann, USA) according to the international federation of clinical chemistry and laboratory medicine (21).

The data obtained were subjected to receiver operating characteristic (ROC) analysis (to determine sensitivity and specificity), MannWhitney $U$ test for comparison of variables and Karl-Pearson's test to assess coefficient correlation. All statistical analyses were performed using SPSS Package version 23.0 (SPSS Inc, Chicago, USA). A ROC/area under the ROC curve (AUC) score of greater than 0.7 indicated significant correlation between serum and saliva samples.

\section{RESULTS}

Demographic characteristics of study subjects are presented in table 1 . The levels of AST $($ saliva $=25.8 \pm 17.9 \mathrm{U} / \mathrm{L}$, serum $=23.0$ $\pm 6.4 \mathrm{U} / \mathrm{L}$ ) did not differ significantly between saliva and serum samples ( $\mathrm{t}$-test $\mathrm{P}=0.347)$. In contrast, ALP, ALT, GGT, urea, total bilirubin And creatinine levels were higher was statistically significant between saliva and serum samples (t-test $\mathrm{P}=0.000$ ) (Table 2 ). The ROC analysis revealed that AST has a score of 0.717, which is greater than the cut-off threshold value of 0.7 , indicating the potential of AST as marker in saliva (Figure 1). The mean saliva to serum ratio values for AST was $111.9 \%$, which means that AST is secreted in saliva in high amounts. In addition, the specificity and sensitivity of salivary AST were $80 \%$ and $76 \%$, respectively. The cut-off point for AST was 31.5, suggesting that normal range of salivary AST is $31.5-110$ U/L. The number of samples needed for accurate statistical ranges were 46 , which were covered in our study.

The significant ROC scores of GGT (0.76) and urea (0.86) indicated their potential use as markers for investigating liver function and kidney function using saliva. According to the ROC curve AUC, GGT had a sensitivity of $80 \%$ and a specificity of $63.4 \%$. The suggested normal range of salivary GGT was determined to be 10.5-24.5 U/L. The number of samples needed to give an accurate statistical range was 20 samples, which were covered in our study.

For urea, the mean saliva to serum ratio was $129.6 \%$, which means that urea is also secreted in saliva in high amounts. The AUC indicated that salivary urea had a sensitivity of $100 \%$ and a specificity of $75.3 \%$. The suggested normal range of salivary urea was 46 to 75 $\mathrm{mg} / \mathrm{dL}$. The number of samples needed to give an accurate statistical range was 17 samples, which were covered by our study population. The suggested normal ranges of salivary ALP, ALT, total bilirubin and creatinine were 7-98 $\mathrm{U} / \mathrm{L}, 6-31 \mathrm{U} / \mathrm{L}, 0-0.13 \mathrm{mg} / \mathrm{dL}$ and $0.14-0.31$ $\mathrm{mg} / \mathrm{dL}$, respectively (Table 3 ).

Table 1. Demographical characteristics of participants

\begin{tabular}{cc}
\hline Variable & Value \\
\hline Average age (years) & $24 \pm 4.8$ \\
Average weight $(\mathbf{k g})$ & $66.35 \pm 12.44$ \\
Sex & \\
Male & $\mathrm{N}=43$ \\
Female & $\mathrm{N}=57$ \\
Smoking & \\
Yes & $\mathrm{N}=22$ \\
No & $\mathrm{N}=78$ \\
\hline
\end{tabular}


Table 2. Salivary and serum levels of liver function and kidney function biochemical parameters in subjects

\begin{tabular}{|c|c|c|c|c|}
\hline Parameter & $\begin{array}{l}\text { Serum level } \\
\text { (Mean } \pm \mathrm{SD})\end{array}$ & $\begin{array}{l}\text { Salivary level } \\
\text { (Mean } \pm \mathrm{SD})\end{array}$ & $\begin{array}{l}\text { t-test } P \text { - } \\
\text { value }\end{array}$ & $\begin{array}{c}\text { ROC/AUC } \\
\text { value }\end{array}$ \\
\hline ALP & $146.9 \pm 35(\mathrm{U} / \mathrm{L})$ & $20.9 \pm 20.7$ (U/L) & 0.000 & 0.44 \\
\hline AST & $23 \pm 6.4(\mathrm{U} / \mathrm{L})$ & $25.8 \pm 17.9(\mathrm{U} / \mathrm{L})$ & 0.347 & 0.72 \\
\hline ALT & $16.25 \pm 8.6(\mathrm{U} / \mathrm{L})$ & $10.6 \pm 11.8(\mathrm{U} / \mathrm{L})$ & 0.000 & 0.50 \\
\hline GGT & $21.5 \pm 5.2(\mathrm{U} / \mathrm{L})$ & $9.6 \pm 4.37$ (U/L) & 0.000 & 0.76 \\
\hline Total Bilirubin & $0.83 \pm 0.12 \mathrm{mg} / \mathrm{dL}$ & $0.16 \pm 0.13 \mathrm{mg} / \mathrm{dL}$ & 0.000 & 0.49 \\
\hline Creatinine & $0.635 \pm 0.27 \mathrm{mg} / \mathrm{dL}$ & $0.087 \pm 0.05 \mathrm{mg} / \mathrm{dL}$ & 0.000 & 0.556 \\
\hline UREA & $27.5 \pm 7.24 \mathrm{mg} / \mathrm{dL}$ & $35.6 \pm 15.19 \mathrm{mg} / \mathrm{dL}$ & 0.000 & 0.826 \\
\hline
\end{tabular}

Table 3. Normal range and sensitivity/specificity of the tested biochemical parameters for saliva testing

\begin{tabular}{|c|c|c|c|c|c|c|c|}
\hline Variable & $\begin{array}{l}\text { ALP } \\
\text { (U/L) }\end{array}$ & $\begin{array}{l}\text { ALT } \\
\text { (U/L) }\end{array}$ & $\begin{array}{l}\text { AST } \\
(\mathrm{U} / \mathrm{L})\end{array}$ & $\begin{array}{c}\text { Urea } \\
(\mathrm{mg} / \mathrm{dL})\end{array}$ & $\begin{array}{c}\text { Total } \\
\text { Bilirubin } \\
(\mathrm{mg} / \mathrm{dL})\end{array}$ & $\begin{array}{l}\text { GGT } \\
\text { (U/L) }\end{array}$ & $\begin{array}{c}\text { Creatinine }(\mathrm{mg} / \\
\mathrm{dL})\end{array}$ \\
\hline Normal range & $7-98$ & $6-31$ & $31-104$ & $45-74$ & $0-0.13$ & $15-24$ & $0.14-0.31$ \\
\hline Sensitivity\% & 38 & 75 & 80 & 100 & 49 & 60 & 20 \\
\hline Specificity \% & 85 & 45 & 76 & 75 & 38 & 91 & 91 \\
\hline $\mathrm{CV} \%$ & 92 & 107 & 74 & 43 & 69 & 44 & 51 \\
\hline
\end{tabular}

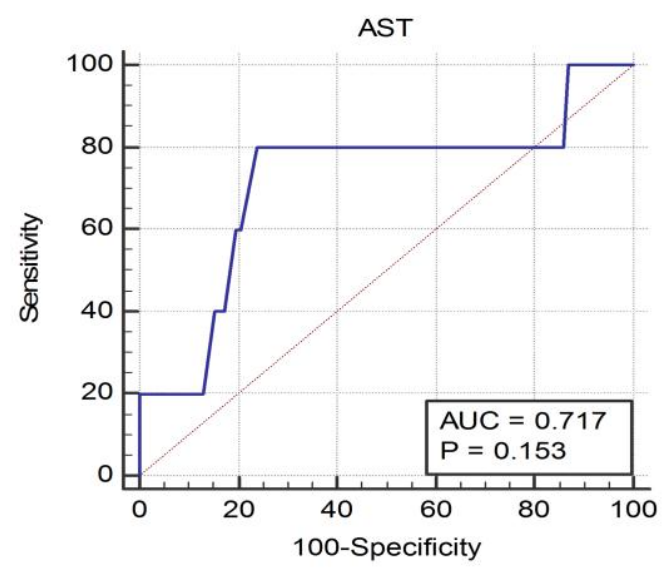

Figure 1. The ROC curve of AST 


\section{DISCUSSION}

This study was conducted to investigate efficacy of saliva for evaluation of certain biochemical markers in healthy individuals in Jordan. We also aimed to normalize urea to amylase levels in each saliva sample to determine whether normalization is needed to reduce variability of results. We found that variability of salivary urea was increased from $43 \%$ to over $300 \%$, which indicated that normalization of saliva samples is not necessary.

It has been reported that AST and ALT levels are usually equal in serum and saliva of different population, regardless of the underlying clinical condition (22). A study conducted by Bilancio et al. revealed a significant correlation between saliva and serum urea levels, which may be related to the high solubility and diffusive nature of urea (22). In a study by Kovalčíkova et al., saliva urea and creatinine was higher in patients with chronic kidney disease than in age-matched healthy controls. In addition, there was a positive correlation between serum/plasma and salivary concentrations of creatinine and urea in the patients (23). In contrast, Peng et al. demonstrated that salivary urea concentrations are almost identical in the morning and

\section{REFERENCES}

1. Javaid MA, Ahmed AS, Durand R, Tran SD. Saliva as a diagnostic tool for oral and systemic diseases. J Oral Biol Craniofac Res. 2016; 6(1): 66-75.

2. Rahim MAA, Rahim ZHA, Ahmad WZW, Hashim $\mathrm{OH}$. Can saliva proteins be used to predict the onset of acute myocardial infarction among high-risk patients? Int J med sci. 2015; 12(4): 32935. doi: 10.7150/ijms.11280.

3. Cheng Y-SL, Rees T, Wright J. A review of research on salivary biomarkers for oral cancer detection. Clin translati medi. 2014; 3(1): 3. doi: 10.1186/2001-1326-33.

4. Kaczor-Urbanowicz KE, Martin Carreras-Presas C, Aro K, Tu M, Garcia-Godoy F, Wong DT. Saliva Diagnostics-Current views and directions. Exp Biol Med (Maywood). 2017; 242(5): 459-472. doi: $10.1177 / 1535370216681550$.

5. Kaufman E, Lamster IB. The diagnostic applications of saliva $-A$ review. Critical Reviews in Oral Biology and Medicine. 2002; 13: 197-212.

6. de Almeida Pdel V, Grégio AM, Machado MA, de Lima AA, Azevedo LR. Saliva composition and functions comprehensive review. J Contemp Dent Pract. 2008; 9(3): 72-80.

7. Malathi N, Mythili S, Vasanthi HR. Salivary diagnostics: a brief review. ISRN Dent. 2014; 2014: 158786. doi: 10.1155/2014/158786. afternoon, suggesting that the concentration of saliva urea is independent of serum urea level (24).In a study by Ivanovski et al., accumulation of creatinine in the blood due to kidney disease increased a concentration gradient that facilitated creatinine diffusion to saliva. Moreover, high plasma creatinine increases the permeability of salivary glands $(25,26)$.

One of the major limitations of the present study was the lack of a comparative patient's group with age-matched healthy individuals. It is recommended to compare the salivary levels of AST, GGT and urea between patients with different hepatic and renal disorders.

\section{CONCLUSION}

Saliva constitutes a robust surrogate for urea, GGT and AST testing in humans.

\section{ACKNOWLEDGMENTS}

This research was funded by Deanship of higher education and scientific researchUniversity of Petra. Special thanks are extended to our colleagues Miss Suzan Alwawi and Dr. Mohammad Malkawi of UPPC for their continuous technical support. We would like to thank Mr. Omar Abu-Duhair for helping in saliva sampling.

\section{CONFLICT OF INTEREST}

The authors declare that there is no conflict of interest.

8. Chiappin S, Antonelli G, Gatti R, De Palo EF. Saliva specimen: A newlaboratory tool for diagnostic and basic investigation. Clinica Chimica Acta. 2007; 383(1-2): 3040.

9. Zhang CZ, Cheng XQ, Li JY, Zhang P, Yi P, Xu X, et al. Saliva in the diagnosis of diseases. Int J Oral Sci. 2016; 8(3): 133-137. doi: 10.1038/ijos.2016.38.

10. Peng CH, Xia YC, Wu Y, Zhou ZF, Cheng P, Xiao P, et al. Influencing factors for saliva urea and its application in chronic kidney disease. Clin Biochem. 2013; 46(3): 275-7. doi: 10.1016/j.clinbiochem.2012.10.029.

11. Hoffman LF. Human saliva as a diagnostic specimen. J Nutr. 2001; 131:1621S-5S.

12. Kaufman E, Lamster IB. The diagnostic applications of saliva: a review. Crit Rev Oral Biol Med. 2002; 13(2): 197-212.

13. Spielmann N, Wong DT. Saliva: Diagnostics and therapeutic perspectives. Oral Diseases. 2011; 17(4): 345-354. doi: 10.1111/j.1601-0825.2010.01773.x.

14. Chiappin S, Antonelli G, Gatti R, De Palo EF. Saliva specimen: A new laboratory tool for diagnostic and basic investigation. Clinica Chimica Acta. 2007; 383(1-2): 3040. DOI: 10.1016/j.cca.2007.04.011.

15. Pfaffe T, Cooper-White J, Beyerlein P, Kostner K, Punyadeera C. Diagnostic potential of saliva: current state and future applications. Clin Chem. 2011; 57(5): 675-87. doi: 10.1373/clinchem.2010.153767. 
16. Rehman AS, Khurshid Z, Hussain Niazi F, Naseem M, Al Waddani H, Sahibzada HA, et al. Role of Salivary Biomarkers in Detection of Cardiovascular Diseases (CVD). Proteomes. 2017; 5(3): pii: E21. doi: 10.3390/proteomes5030021.

17. Mittal S, Bansal V, Garg S, Atreja G, Bansal s, et al. The diagnostic role of Saliva - A Review. J Clin Exp Dent. 2011; 3(4): e314-20. DOI: 10.4317/jced.3.e314.

18. Lasisi TJ, Raji YR, Salako BL. Salivary creatinine and urea analysis in patients with chronic kidney disease: a case control study. BMC nephrology. 2016; 17(1): 10. DOI: 10.1186/s12882-016-0222-x.

19. Nunes S, Alessandro L, Mussavira S, Sukumaran Bindhu O. Clinical and diagnostic utility of saliva as a non-invasive diagnostic fluid: a systematic review. Biochemia Medica. 2015; 25: 177-92.

20. Malamud D. Saliva as a diagnostic fluid. Dent Clin North Am. 2011; 55(1): 159-78. doi: 10.1016/j.cden.2010.08.004.

21. ACE Alera ${ }^{\circledR}$ Performance Characteristics. Alfa Wassermann Open Channel Application Kits. www.AlfaWassermannUS.com
22. Bilancio G, Cavallo P, Lombardi C, Guarino E, Cozza V, Giordano F, et al. Salivary levels of phosphorus and urea as indices of their plasma levels in nephropathic patients. J Clin Lab Anal. 2018; 32(7): e22449. doi: 10.1002/jcla.22449.

23. Kovalčíková A, Janšáková $K$, Gyurászová $M$, Podracká L, Šebeková K, Celec P, et al. Salivary creatinine and urea are higher in an experimental model of acute but not chronic renal disease. PLoS ONE. 2018; 13(7): e0200391.

24. Peng CH, Xia YC, Wu Y, Zhou ZF, Cheng P, Xiao P. Influencing factors for saliva urea and its application in chronic kidney disease. Clin Biochem. 2013; 46(3): 2757. doi: 10.1016/j.clinbiochem.2012.10.029.

25. Ivanovski K1, Naumovski V, Kostadinova M, Pesevska S, Drijanska K, Filipce V. Xerostomia and salivary levels of glucose and urea in patients with diabetes. Prilozi. 2012; 33(2): 219-29.

26. Khanum N, Mysore-Shivalingu M, Basappa S, Patil A, Kanwar S, et al. Evaluation of changes in salivary composition in renal failure patients before and after hemodialysis. Journal of Clinical and Experimental Dentistry. 2017; 9(11): e1340-e1345. doi: $10.4317 /$ jced.54027.

\section{How to Cite:}

This paper should be cited as: Idkaidek NM, Qawasmi HA, Hanahen AA, Abu-Qatouseh LF, Hamadi SA, Bustami MM. [Applicability of Saliva for Evaluation of Some Biochemical Parameters of Kidney and Liver Function in Healthy Individuals]. mljgoums. 2020; 14(4): 1-6. DOI : $10.29252 / \mathrm{mlj} .14 .4 .1$ 